\title{
Correction to: Survey of two artichoke moths "Gortyna xanthenes (Germar) and Depressaria erinaceella (Staudinger)" in Tunisia
}

\author{
Asma Cherif $^{1}\left[{ }^{\mathbb{D}} \cdot\right.$ Rania Aissani $^{1} \cdot$ Oumayma Aroua ${ }^{1} \cdot$ Manel Bouhadida-Mhadhbi $^{2} \cdot$ Kaouthar Grissa-Lebdi $^{1}$
}

Published online: 13 June 2020

(c) Deutsche Phytomedizinische Gesellschaft 2020

Correction to: Journal of Plant Diseases and Protection https://doi.org/10.1007/s41348-020-00339-5

The names of the varieties cultivated in the two study regions were given wrongly in the Materials and Methods section. The correct names are as follows.

Varieties used in Essaida (Northern Tunisia, Governorate of Manouba): "Blanc Oranais" and "Violet d'Hyères"

Variety used in Sidi-Thabet (Northern Tunisia, Governorate of Ariana): "Violet d'Hyères"

The authors apologize for the mistake.

Publisher's Note Springer Nature remains neutral with regard to jurisdictional claims in published maps and institutional affiliations.

The original article can be found online at https://doi.org/10.1007/ s41348-020-00339-5.

Asma Cherif

cherifasma13@yahoo.fr

1 Laboratory of Entomology-Acarology, Department of Plant Protection and Post-Harvest Diseases, National Agronomic Institute of Tunisia, University of Carthage, 43 Avenue Charles Nicolle, Cité Mahrajène, 1082 Tunis, Tunisia

2 Potato and Artichoke Technical Center, Road Jedaida Essaida, 2031 Manouba, Tunisia 